\title{
NOTAS CRÍTICO-SOCIOLÓGICAS SOBRE A LITERATURA COMO HORIZONTE DE HUMANIZAÇÃO
}

\section{CRITICAL-SOCIOLOGICAL NOTES ON LITERATURE AS A HORIZON OF HUMANIZATION}

\author{
Wilder Kleber Fernandes de Santana ${ }^{1}$ \\ Weslei Chaleghi de Melo
}

Recebido em: 18 abr. 2020.

Aceito em: 30 mai. 2020.

DOI 10.26512/aguaviva.v5i3.31020

RESUMO: Este trabalho se propõe a tecer notas crítico-sociológicas sobre a literatura como horizonte de humanização em que buscamos discutir considerações voltadas à literariedade, interligadas ao constituir-se humano. A vertente crítico-sociológica impulsiona cientistas da linguagem a imergir na história e na memória sociais para compreender processos de constituição das produções (de linguagem) contemporâneas. Para tanto, a pesquisa buscou subsídios teórico-metodológicos nos postulados de Candido (2009), Compagnon (2009), Cosson (2007) e Lajolo (2003), dentre outros, os quais desenvolvem um pensamento com base na alteridade e nas interrelações eu-outro. Em aspectos estruturais, o manuscrito está dividido em 2 seções. A primeira, intitulada Notas crítico-sociológicas sobre o papel humanizador da Literatura, contém reflexões sobre o potencial humanizador e transformacional da Literatura, alicerçadas nos dizeres de Candido $(1972 ; 1985)$, em diálogo com interlocutores. A segunda seção, A caminho da humanização pela Alteridade: análises de obras, abarca a análise de manuscritos em que é possível observar a concretização do processo humanizador da literatura, via domínios artísticos integradores do humano.

Palavras-chave: Literatura. Humanização. Notas crítico-sociológicas.

ABSTRACT: This paper proposes to bring critical-sociological notes about literature as a horizon of humanization in which we seek to discuss considerations focused on literariness, interconnected to becoming human. The critical-sociological aspect encourages language scientists to immerse themselves in social history and memory to understand the processes of constitution of contemporary (language) productions. To this end, the research seeks theoretical and methodological subsidies in the postulates of Candido (2009), Compagnon (2009), Cosson (2007) and Lajolo (2003), among others, who develop a thought based on alterity and

\footnotetext{
${ }^{1}$ Mestre em Linguística - Universidade Federal da Paraíba (UFPB). É membro pesquisador do Grupo de Pesquisa em Linguagem, Enunciação e Interação - GPLEI-UFPB. ORCID: http://orcid.org/0000-0001-7569-499X. E-mail: wildersantana92@gmail.com

${ }^{2}$ Mestre em Ensino de Ciências Humanas, Sociais e da Natureza pela Universidade Tecnológica Federal do Paraná (UFTPR). É membro pesquisador do Grupo de Pesquisa Multiletramentos: teorias, práticas e formação docente. ORCID: http://orcid.org/0000-0002-0503-6729. E-mail: weslei@alunos.utfpr.edu.br
} 
interrelationships with the other. In structural aspects, the manuscript is divided into 2 sections. The first, entitled Critical-sociological notes on the humanizing role of Literature, contains reflections on the humanizing and transformational potential of Literature, based on the words of Candido (1972; 1985), in dialogue with interlocutors. The second section, On the way to humanization through Alterity: analysis of works, includes the analysis of manuscripts in which it is possible to observe the concretization of the humanizing process of literature, through artistic domains that integrate the human.

Keywords: Literature. Humanization. Critical-sociological notes.

\section{INTRODUÇÃO}

O presente manuscrito delimitou, como objetivo principal, tecer notas críticosociológicas sobre a literatura como horizonte de humanização, e, apesar de não ser uma tarefa fácil, buscamos discutir considerações voltadas à literariedade ${ }^{3}$, interligadas ao constituir-se humano. Dessa forma, nosso horizonte de estudos está situado entre os aspectos subjetivo e objetivo $^{4}$, posto que não há uma fórmula pronta e acabada para abarcar o terreno da literatura. Apesar de não haver pioneirismo em nossa proposta, uma vez que diversas pesquisas têm sido efetivadas refletindo sobre a humanização provocada pela literatura (MATHEUS, 2019; SANTANA \& SILVEIRA, 2019; SCHEIDT, 2019), buscamos nos inserir nesse povoamento de vozes com a singularidade de nosso ato, na tentativa de contribuir com discursos já existentes.

Nossas proposições ganham respaldo principalmente nos postulados de Candido, o qual se interroga, em Literatura e Sociedade: "qual a influência exercida pelo meio social sobre a obra de arte?" (CANDIDO, 1985, p. 18). Ao refletirmos, então, sobre tal interrogativa, corroboramos os dizeres de Santana \& Silveira, para quem "Tais reflexões consistem na

\footnotetext{
${ }^{3}$ Gumbrecht e Jobim (2002) acreditam que as concepções sobre a literariedade de uma obra estão respaldadas em experiências anteriores, construída sobre uma tradição que a estabelece e a enquadra dentro do cânone. No entanto, não apenas corroborando essa visão, mas excedendo-a, com base em Candido (1972), compreendemos a literalidade como um processo de demarcação histórico-cultural, cujas diferenças entre obras se dão em uma perspectiva específica das realidades vivenciadas por cada autor/personagem.

${ }^{4}$ Quando mencionamos que a delimitação de nosso objeto de estudo está entre os aspectos objetivo e subjetivo, estamos respaldados no pensamento crítico-sociológico de Volóchinov, estudioso russo e integrante do círculo de Bakhtin, especificamente em seus escritos introdutórios sobre como a ciência das ideologias incide na importância dos problemas da Filosofia da Linguagem para o Marxismo. Ao atuar como importante crítico e influenciar fortemente os estudos da linguagem na primeira metade do século XX, Volóchinov propôs a superação de duas tendências de estudos literários e linguísticos: "o objetivismo abstrato ou positivista e o subjetivismo idealista. Assim, ao tecer uma crítica ao objetivismo abstrato, Volóchinov justificou que as práticas do discurso nesse sistema consistem em uma anulação do sujeito falante. Posto que o objetivismo tenha sido uma herança de tradição filosófica racionalista já presente em Descartes2 (1596 - 1650) e Leibniz3 (1646 - 1716), esta corrente postula que os sujeitos já recebem a língua finalizada em seus próprios significados, pois é transmitida aos seres humanos estando pronta para ser utilizada" (SANTANA, 2019, p. 207).
} 
máxima candidiana a respeito da literatura enquanto fenômeno artístico e humanizador" (SILVEIRA; SANTANA, 2019, p. 75).

Venâncio ${ }^{5}$ (2009), em seus estudos, salienta que a literatura proporciona o sentimento de alteridade aos leitores. De fato, coloca-se no lugar do outro, daquele que me é diferente é a manifestação da alteridade - constituinte das bases de uma sociedade mais justa -. Justamente essa concepção relativa e dialógica entre o eu e outro que compreendemos como horizonte de humanização. Desse modo, a literatura impulsiona sujeitos a agirem dialogicamente ${ }^{6}$, na medida em que evidencia aspectos constituintes das dimensões ética e estética humana (BAKHTIN, 2006 [1979]). Como postula o crítico literário Harold Bloom (2001), ela proporciona, de certa forma, a construção de sujeitos providos de razão para pensar e agir criticamente em seu meio social. Reconhece-se que nem toda obra literária proporciona as reflexões desejadas, cabendo aos pesquisadores e críticos selecioná-las para que a leitura tenha finalidades que perpassem a apreciação estética e desconstruam, de fato, velhos paradigmas sociais. Assim, como toda produção artística, pode potencialmente possibilitar o desenvolvimento da construção da identidade, e, consequentemente, a distinção entre o "eu" e o “outro" (BAKHTIN, 2006 [1979]).

Portanto, reconhecer a literatura como horizonte de humanização deve pressupor o incentivo à reflexão crítica, além de discussões/diálogos entre autor e leitor, pois, conforme nos aponta Todorov, "ela permite que cada um responda melhor à sua vocação de ser humano" (TODOROV, 2010, p. 53). Nesse direcionamento argumentativo, subsidiamos nossos dizeres principalmente nos postulados de Candido (2009), Compagnon (2009), Cosson (2007) e Lajolo (2003), dentre outros, os quais desenvolvem um pensamento com base na alteridade e nas interrelações eu-outro. De igual modo, a partir dos ditos e escritos dos estudiosos, buscamos respaldo teórico em interlocutores nos terrenos da literatura e do discurso.

\footnotetext{
${ }^{5} \mathrm{Na}$ ótica de Venâncio, o leitor busca, no seu contato com o objeto livro, uma conexão com outras experiências de vida, procurando compreender o que é ser o outro, estar em terras longínquas, ter outro sexo, peregrinar e ter modos diferentes de enxergar o mundo. Assim, a literatura infantojuvenil, como outros gêneros literários, é constituída como um importante artefato cultural difusor de mensagens, ao reforçar atitudes, legitimar discursos e fortalecendo estigmas, mantendo ideologias (VENÂNCIO, 2009, p. 53).

6 Agir dialogicamente, em perspectiva bakhtiniana, pressupõe a existência de relações dialógicas, cujo desenvolvimento se dá, dentre outros, no escrito de Bakhtin Problemas da obra de Dostoiévski, texto datado de 1929; e em sua edição mais recente e revisada Problemas da poética de Dostoiévski, de 1963 (2005). Direcionado a estudar e compreender relações entre a vida e a arte no âmbito literário, nessas obras, Bakhtin analisa uma série de procedimentos discursivos que constituem Dostoiévski enquanto sujeito-autor, na medida em que este empreende a literatura como horizonte de múltiplas vozes no processo criativo de elaboração de seus romances.
} 
Em termos estruturais, o manuscrito está dividido em 2 seções. A primeira, intitulada Notas crítico-sociológicas sobre o papel humanizador da Literatura, contém reflexões sobre o potencial humanizador e transformacional da Literatura, alicerçadas nos dizeres de Candido (1972; 1985), em diálogo com interlocutores. A segunda seção, A caminho da humanização pela Alteridade: análises de obras, abarca a análise de manuscritos em que é possível observar a concretização do processo humanizador da literatura, via domínios artísticos integradores do humano.

\title{
1 Notas crítico-sociológicas sobre o papel humanizador da Literatura
}

Posicionar-se crítico-sociologicamente é, sobretudo, imergir na história e na memória sociais para compreender processos de constituição das produções (de linguagem) contemporâneas. Ainda que o processo gestacional e de nascimento humanos seja entendido por meio de atribuições biológicas, vertentes literário-discursivas (BAKHTIN, 2006 [1979]; VOLÓCHINOV, 2017 [1929]); CANDIDO, 1972) nos conclamam a enxergar a constituição humana pelas lentes da dialética histórico-social, observando as movências espaço-temporais (BAKHTIN, 2018) e de que forma isso é instaurado ideologicamente (MEDVIÉDEV, 2016 [1928]). Assim, compreendemos a arte literatura como elemento constitutivo a partir do qual materializam-se vivências sociais e experiências humanizadoras na qual se inclui a arte literária. Na ótica de Cosson,

\begin{abstract}
A literatura nos diz o que somos e nos incentiva a desejar e a expressar o mundo por nós mesmos. E isso se dá porque a literatura é uma experiência a ser realizada. É mais que um conhecimento a ser reelaborado, ela é a incorporação do outro em mim sem renúncia da minha própria identidade. No exercício da literatura, podemos ser outros, podemos viver como os outros, podemos romper os limites do tempo e do espaço de nossa experiência e, ainda assim, sermos nós mesmos. É por isso que interiorizamos com mais intensidade as verdades dadas pela poesia e pela ficção (COSSON, 2007, p. 17).
\end{abstract}

Negligenciar o acesso à literatura nas escolas é cometer um "crime" contra o sujeito que necessita do contato com a leitura literária. Identificar-se com personagens faz com que os alunos enfrentem suas incertezas, angústias e inquietações, além de ser um "ensaio" para o mundo real. Compreendemos que em parte considerável das instituições de ensino brasileiras, ainda se percebe que a configuração do ensino de literatura é permeada pelo sistema de valor(es) estético(s) e instituída com base em uma tradição canônica. Dessa forma, os estudantes passam 
a, geralmente, valorizar uma obra sem saber o motivo. Para Candido (2004), tal reprodução não reflexiva do cânone constitui uma grande limitação para o desenvolvimento da criticidade do leitor. Dentro desse estabelecimento de uma cultura literária, encontramos instâncias legitimadoras que contribuem para a articulação do cânone literário. Entre eles, as Universidades, que, com seus vestibulares, reforçam as obras de autores que tiveram historicamente firmado seu valor literário. Essa relação, em consonância com as cobranças de leituras para o Ensino Médio, estabelece determinadas narrativas literárias que devem ser estudadas, solidificando uma tradição do que pode ser considerado literatura, quando não, uma "boa literatura” (MELO; PIMENTEL, 2018).

Candido também argumenta, sobre a elevação do nível de compreensão do texto literário, que a leitura deve partir de diferentes formas e temáticas, em variados níveis de complexidade e qualidade (CANDIDO, 1972). Isso fará com que se amadureça o grau interpretativo, alçando comparações com critérios cada vez mais rigorosos referentes à estética da obra lida (CANDIDO, 1985). Candido se posiciona fortemente sobre a necessidade de o homem assumir responsabilidades para com o fazer literário via alteridade, em representações da realidade social. Em Ciência e Cultura, o sociólogo afirma que essa interrelação entre a realidade e o imaginário

[S]erve para ilustrar em profundidade a função integradora e transformadora da criação literária com relação aos seus pontos de referência na realidade. Ao mesmo tempo, a evocação dessa impregnação profunda mostra como as criações ficcionais e poéticas podem atuar de modo sub-consciente e inconsciente, operando uma espécie de inculcamento que não percebemos (CANDIDO, 1972, p. 805).

É nesse movimento de compreensão que a uma obra literária, para Lajolo (2003, p.45), não deve ser concebida apenas como um conjunto de elementos imanentes com suas próprias características, nem um objeto "identificado apenas pelos aspectos internos do texto", mas sobretudo "[...] como integração de autores, obras e público em um sistema articulado e não mais como pluralidade aleatória [...]" (LAJOLO, 2003, p. 56). Empreendem então, Santana \& Silveira $(2019$, p.80) que “Ao contrário, tais textos literários são produzidos em meio a processos de (des)legitimação ideológica, em interação entre autor, leitor(es) presumido(s), público, condições de produção e os ambientes em que circula".

Acrescentamos o que Harold Bloom (1995, p. 31) afirma: "Eu próprio insisto em que o eu individual é o único método e todo o padrão para a apreensão do valor estético”. Ainda, para ele, essa visão elitista da literatura vem se perpetuando ao longo dos tempos pela crítica literária, 
um dos pilares que classifica o que recebe o título de "literatura" ao enquadrar a obra como boa ou ruim, tendo como base unicamente seu valor estético, grau de autoria, e atemporalidade fato de algumas obras terem a capacidade de se perpetuar como as mais lidas durante o tempo e, mesmo fora do seu contexto histórico de produção, ainda assim, traz significações e ressignificações aos seus leitores -. No que diz respeito à humanização, conforme mencionamos, esta instaura-se entre as fronteiras subjetiva e objetiva de cada sujeito. Desse modo, "Assim como não é possível haver equilíbrio psíquico sem o sonho durante o sono, talvez não haja equilíbrio social sem a literatura" (CANDIDO, 2004, p. 176).

Notamos, portanto, que processos de humanização, em sua essência, podem ser alcançados pela arte, alinhada e interligada à literatura (MEDVIÉDEV, 2016 [1928]). Para Schiller (1991), a literatura (re)estrutura os sentimentos contidos no interior do ser humano, no tocante de seu inconsciente e subconsciente, em seus anseios e medos mais profundos ${ }^{7}$. É nessa esteira de excedente de visão que, para Compagnon (2009, p. 36), a literatura "dota o homem moderno de uma visão que nos leva para além das restrições da vida cotidiana”. Sendo assim, ela é fruto de um contexto social e nosso cotidiano é indissociável das manifestações ficcionais ou poéticas. Ora, se ela está presente em nosso dia a dia, torna-se um bem social que deve ser para todos (CANDIDO, 2004).

Para Melo e Pimentel (2018), ao a subjetividade da literatura correlaciona-se ao conceito de valor da obra, em um processo (des)contínuo de definições e características que destacam determinada narrativa literária. A literatura, assim como o cinema, associa-se ao uso de imagens produzidas, visualmente ou até mesmo subjetivamente, por meio da imaginação. Por exemplo, bons romances e poemas possibilitam que, mesmo sem recursos visuais, a não ser sinais gráficos, e via imaginação, seja possível formar figuras com propriedades singulares, que possuam elementos em comum em todos os que a ouvem/leem (BOSI, 1974).

A Teoria da Forma ensina que a imagem tende (para nós) ao estado de sedimento, de quase-matéria posta no espaço da percepção, idêntica a si mesma. Cremos "fixar" o imaginário de um quadro, de um poema, de um romance. Quer dizer: é possível pensar em termos de uma constelação se não de um sistema de imagens, como se pensa em um conjunto de astros. Como se o objeto e imagem fossem dotados de propriedades homólogas (BOSI, 1974, p. 67).

\footnotetext{
${ }^{7}$ Tal processo não é inovador, mas consiste em um retorno a práticas primitivas, uma vez que, conforme Fischer, no período pré-histórico "Nos alvores da humanidade a arte pouco tinha a ver com "beleza" e nada tinha a ver com a contemplação estética: era um instrumento mágico, uma arma da coletividade humana em sua luta pela sobrevivência" (FISCHER, 1987, p. 45). Desse modo, no escopo das sociedades primitivas, o foco artístico estava na base fundamental de representação de suas crenças, valores, costumes, e modus vivendi.
} 
Nesse direcionamento argumentativo, por meio da produção crítica de Candido (1972; 1985), corroboramos a existência de uma literatura humanizadora, com aspectos singulares, marcadas muitas vezes pelo pertencimento espaço-temporal. Afirma o estudioso que a Literatura

[é] um sistema vivo de obras, agindo umas sobre as outras e sobre os leitores; e só vivem na medida em que estes a vivem, decifrando-a, aceitando-a, deformando-a. [...] a obra de arte só está acabada no momento em que se repercute e atua, porque 4 sociologicamente, a arte é um sistema simbólico de comunicação inter-humana. Ora, todo processo de comunicação pressupõe um comunicante, no caso o artista; um comunicado, ou seja, a obra; um comunicando, que é o público a que se dirige; graças a isso define-se o quarto elemento do seu processo, isto é, o seu efeito (CANDIDO, 1985, p. 25).

Nesse sentido, ancorados em uma perspectiva crítico-sociológica (VOLÓCHINOV, 2017 [1929]) da linguagem, é-nos necessário recorrer à sociologia moderna, segundo a qual “[...] interessa principalmente analisar os tipos de relações e os fatos estruturais ligados à vida artística, como causa ou consequência [...] investigar as influências concretas exercidas [sobre a arte] pelos fatores socioculturais" (CANDIDO, 1985, p. 21). Ao imergirmos nos fatores culturais refletidos e refratados na literatura,

[P]rocuraríamos determinar se ele fornece apenas matéria (ambiente, costumes, traços grupais, ideias), que servem de veículo para conduzir a corrente criadora (nos termos de Lukács, se apenas possibilita a realização do valor estético); ou se, além disso, é elemento que atua na constituição do que há de essencial na obra enquanto obra de arte (nos termos de Lukács, se é determinante do valor estético) (CANDIDO, 1985, p. 05).

É então que a literatura se instaura como horizonte humanizador, na medida em que incide sobre problematizações e particularidades espaço-temporais que engendram o humano. Processos de humanização não apenas recorrem a condições históricas de produção dos enunciados, mas reinsere-os em novas cadências de acontecimentos sob vértices literários. Corroboramos, dessa forma, com o pensamento de Buoro (2000), o qual atesta que as invenções humanas seriam “filhas das épocas em que acontecem, pois não há descoberta cientifica ou produção artística sem que existam condições materiais e psicológicas favoráveis ao seu aparecimento" (BUORO, 2000, p. 82). Assim, "elas sempre se apoiam em acontecimentos anteriores, inscritos em um processo histórico" (BUORO, 2000, p. 82).

\section{A caminho da humanização pela literatura: análises de obras}


Para concretização dessa seção, delimitamos como corpus duas obras, sendo uma vernácula - o Romance XVI ou da traição do conde ${ }^{8}$, de Cecília Meireles - e outra estrangeira - Elmer, o elefante xadrez (2009) - nas quais é possível averiguar incidências de humanização.

No que concerne ao Romance XVI ou da traição do Conde, o enredo consiste na chegada do Conde de Valadares2 a Minas para decretar a prisão do contratador de diamantes João Fernandes (1720 - 1779) - sendo esse considerado o amante de Chica da Silva. Fato é que, após a chegada do Conde e o explanar de algumas ameaças por parte deste, Cecília Meireles enquanto autora criadora, presta voz a Chica da Silva, escrava e negra:

\author{
Mas, entre as doze mulatas \\ que a servem, resmunga a Chica: \\ "Oxalá não traga o próprio \\ más novidades da Vila. \\ Tenho o coração parado \\ como se não fosse viva... (MEIRELES, 2005, p. 53-54)
}

Quando, na estrofe anteposta, a personagem Chica ganha voz e enuncia "Oxalá não traga o próprio/ más novidades da Vila”, e a personagem Chica se posiciona, seus anseios ganham sentidos plurais. Nossa intenção não é analisar o poema, mas perceber que, por meio dessa construção literário-artística, Cecília Meireles inclui esse outro cujas condições de gênero, raciais, econômicas e de classe eram tão demarcadamente excluídas - mulher, negra, pobre e escrava.

Na ótica de Rocha (2010, p. 03), "a multiplicidade dos sentidos admitida pelo texto literário exige uma discussão sobre os limites e as potencialidades do sentido, discussão respaldada pela hermenêutica literária, assunto determinante para a teoria da literatura". Então, o processo de humanização está, nas entrelinhas supramencionadas, em uma perspectiva de conscientização, afinal, Chica da Silva também é um sujeito constituinte da história de Ouro Preto.

A literatura precisa ser bem compreendida pelos sujeitos que a vivenciam no sentido de potencializar seu repertório e, portanto, a ampliar seus horizontes no mundo das letras. Iremos,

\footnotetext{
${ }^{8} \mathrm{O}$ "Romance XVI ou da traição do conde", é um dos vários romances de poesia que integralizam o livro $O$ Romanceiro da Inconfidência (2005 [1953]), de Cecília Meireles, e que refletem as condições histórico-culturais e poéticas de acontecimentos referentes à época da mineração do ouro e dos diamantes, em Ouro Preto - MG. Cecília Meireles (1901-1964) tem reconhecimento por sua obra como uma das mais célebres atuantes da literatura brasileira e das literaturas de língua portuguesa (MELLO, 2009).
} 
aqui, averiguar a concretização do processo humanizador da literatura, via domínios artísticos integradores do humano.

É perceptível que as experiências sociais e individuais se complementam na formação integra do sujeito. Esse movimento cíclico e contínuo inicia-se desde a primeira infância. Assim, Venâncio (2009) postula que se deve incutir desde cedo a concepção da diversidade social. Desse modo, o sujeito cresce pautado em exemplos de atitudes (professores e alunos) havendo o respeito ao "diferente" - representações que defendemos ser possíveis de alcançar por meio da arte, no caso desta pesquisa, a literária.

Quanto ao livro Elmer, o elefante xadrez, logo na capa, observamos um desenho bem chamativo: um elefante xadrez, com um fundo também xadrez e colorido. Reconhecendo a importância da visualidade como complementar da experiência literária, a obra, em suas ilustrações, demarca fortemente elementos ficcionais voltados ao público infantil. A narrativa constrói-se por meio de palavras do dia a dia das crianças e, além disso, possui uma expressividade simbólica marcante.

Ainda sobre a experiência com a obra em questão, ao iniciar a leitura do livro de Mckee (2009), é possível deduzir o efeito produzido, a princípio, nas crianças em relação à obra de estranhamento e, até mesmo de indagações a respeito do seu conteúdo: "Por que um elefante xadrez e colorido?

No início história, Mckee (2009) descreve uma grande manada de elefantes, todos da mesma cor, "cor de elefante" - cinza -, fato que causava desconforto e tristeza em Elmer. Seu diferencial não era apenas ser xadrez e colorido, ou apenas por ter aspectos físicos distinto dos outros elefantes da manada, mas estava em "ser divertido", como nenhum outro elefante.

Quando o pequeno elefante não estava na manada, só havia silêncio e nenhum sorriso. Elmer tenta, por diversas formas, tornar-se da "cor de elefante", porém falha em todas as tentativas e, por fim, aceita-se como diferente e reconhece e valoriza suas especificidades.

Quando Elmer reencontrou os outros elefantes, estavam todos parados, muito quietos. Nenhum deles reparou em Elmer enquanto ele ia andando para o meio da manada. [...] com as risadas a nuvem escura rebentou, e quando a chuva caiu em Elmer seu xadrez foi aparecendo de novo. Os elefantes continuavam a rir, enquanto a água da chuva fazia Elmer voltar ao normal (MCKEE, 2009, p. 07).

Mckee (2009), com sua narrativa, busca demostrar como muitas vezes o próprio sujeito, tido como "diferente", fica à margem da sociedade, excluído. Elmer, por sua vez, era muito 
estimado pelos elefantes da manada, porém por se considerar "diferente" via-se como inferior. Proporcionar discussões e, consequentemente, reflexões para o aluno, de que a diferença não deve solidificar e instituir conceitos hierárquicos, é, de fato, uma grande ferramenta para o processo de aceitação e desenvolvimento da alteridade, da humanização.

Compreender diversas obras literárias, por exemplo, diferentemente do que muitos pensam, não serve apenas para que conheçamos as clássicas que compõem o cânone, mas para que possamos, ativamente, entender os processos socio-históricos e ideológicos que as constituem. Assim, a literatura precisa ser compreendida responsavelmente como forma de apreensão do mundo por meio da arte, uma vez que, de acordo com Bakhtin, alguns materiais adquirem valor estético "depois de iluminados pelo sentido artístico da obra” (BAKHTIN, 2006 [1979], p. 6). Quanto à especificidade da sala de aula, de acordo com Cosson (2007), os alunos precisam compreender que a função da literatura vai além dos conteúdos escolares. Ele faz com que percebamos o mundo com maior criticidade e sensibilidade, ampliando nosso repertório interno. Só assim deixaremos de ser leitores ingênuos, que não refletem criticamente sobre o que foi lido. Para Candido,

[...] o processo que confirma no homem aqueles traços que reputamos essenciais, como o exercício da reflexão, a aquisição do saber, a boa disposição para com o próximo, o afinamento das emoções, a capacidade de penetrar nos problemas da vida, o senso da beleza, a percepção da complexidade do mundo e dos seres, o cultivo do humor. A literatura desenvolve em nós a quota de humanidade na medida em que nos torna mais compreensivos e abertos para a natureza, a sociedade, o semelhante (CANDIDO, 2004, p. 117).

Atualmente, o fato de parecer tão difícil ensinar literatura, reside na maneira pela qual é ensinada: muitos professores ficam presos ao livro didático e, quando trazem algo fora dele, são apenas fragmentos de obras sem nenhum aprofundamento. Não há como apreciar um romance, por exemplo, lendo apenas duas páginas selecionadas pelo professor.

É indubitável que a sociedade é construída pelo estabelecimento das relações dialógicas entre os sujeitos (BAKHTIN, 2006 [1979]). Logo, formar cidadãos críticos e participativos, em meio a um mundo cada dia mais letrado, torna-se uma tarefa imprescindível. Barthes (1978, p. 19) já dizia que “[...] a literatura engrena o saber no rolamento da reflexividade infinita: através da escritura, o saber reflete incessantemente sobre o saber, segundo um discurso que não é mais epistemológico, mas dramático”. E, ao contrário da escrita técnica, muitas vezes estanque, o texto literário é estruturado pela subjetividade do autor, cujo discurso evoca conotações em 
vieses de plurissignificados, uma vez que seus leitores têm a possibilidade de chegar a conclusões distintas. Em suma, a literatura tem o poder de dizer nas entrelinhas, ensinar por meio de analogias e metáforas presentes nos diferentes gêneros literários.

Ao relacionar ambas as modalidades artísticas, o foco principal deve se dar, principalmente, na problematização levantada pelo professor, que, no caso da presente pesquisa, é o tema da diversidade. Então, quando, por exemplo, se propuser trabalhar com o livro Elmer, o Elefante xadrez ${ }^{9}$, as perguntas poderão ser direcionadas à aceitação do outro, às diferenças etc. Não há motivo para questionar os alunos sobre elementos dos livros que não dialoguem com a problematização sugerida sem que se tenha um objetivo pré-definido. Nesse sentido, Barbosa compreende que o limite entre crítica e criação literária está ligada à "[...] operação transformadora da linguagem" (BARBOSA, 2007, p. 45).

Outro ponto importante, ao relacionar ambas as expressões artísticas em sala de aula, é criar condições para que o estudante perceba a proposta de sentido com a sua obra, suas condições de produção e até os diferentes contextos, dentre eles os descritos por Cosson (2007), possibilitando-se diferentes análises da mesma obra: interpretação estética, poética, literária, psicológica, dentre outras. Entender as condições de produção e o público ao qual se destina a obra faz com que os alunos possam perceber as diferentes intencionalidades dela.

Algumas inquietações metodológicas podem ser: será que o livro abordou esse tema como preocupação social ou foi apenas uma estratégia de persuasão? Se foi uma estratégia para obter lucros, a crítica social levantada pelo livro deixa de ser relevante? Questões assim precisam ser levantadas para que os alunos percebam como os filmes e, muitas vezes os livros, fazem parte de uma indústria cultural com fins determinados.

É importante mostrar aos sujeitos leitores outros motivos pelos quais os filmes não servem como parâmetros exclusivos para o entendimento das obras. Um exemplo claro disso são as adaptações de obras escritas, realizadas pelos Studios Disney de forma mais romantizada. É o caso da A Branca de Neve $e^{10}$, que, na sua versão original, é marcada por tons de crueldade, praticamente eliminados da versão animada em 1937. Outro fator que precisa estar claro é que a arte não significa que seja algo voltado para bem, para o respeito e para o espírito humanitário.

\footnotetext{
${ }^{9}$ Obra de literatura infantil escrita e ilustrada por David Mckee, com lançamento da versão original em 1968 e em 1989 recebeu sua versão reduzida. A narrativa fala sobre Elmer, um elefante diferente dos demais da manada, pois ele era xadrez e colorido - explora, de forma lúdica, a questão da discriminação com base nas diferenças.

10 A narrativa inicialmente era de caráter oral - de tradição alemã - e foi compilada pelos irmãos Grimm e publicada entre 1817 e 1822, marcada por momentos de crueldade. Essa versão foi revisitada, em forma de filme, pelos Studios Disney de modo menos cruel. A obra conta sobre uma bruxa má envenena Branca de Neve com uma maçã, fazendo com que ela caia em um sono profundo que só poderá ser desfeito com o beijo do amor verdadeiro.
} 
Todo texto (literário ou fílmico) é ideológico. Não há neutralidade, e os alunos devem ser esclarecidos sobre isso.

Obras literárias têm potencialidades de mudar o mundo para melhor. Blockbusters e best sellers são válidos para uma proposta pedagógica que trabalhe o cinema e obras literárias como ferramentas metodológicas, contudo, na escolha de obras, é importante que se use também produções que estão fora do contexto norte-americano e europeu branco. Ou seja, produções nacionais e regionais, africanas, latino-americanas, asiáticas, dentre outras, que podem ser exploradas, valorizando, assim, o aspecto multicultural e reforçando a diversidade na própria produção de cultura/entretenimento. Isso fará que os alunos possam se desvincular da visão única de dominado/colonizado, percebendo como as produções do Brasil e da América Latina possuem uma riqueza e uma identidade ímpares na produção artística.

Nossa proposta parte de uma concepção de educação que, de acordo com Freire (1987), tem como principal objetivo educar para humanização, de forma que o aluno não seja um mero "habilitado", "competente" e/ou "técnico". O estudante precisa, por meio da cultura historicamente construída, apropriar-se dessa humanização. A esse respeito, pontua Freire que

\begin{abstract}
É que, se os são estes seres da busca e se sua vocação ontológica é humanizarse, podem, cedo ou tarde, perceber a contradição em que a "educação bancária" pretende mantê-los, e engajar-se na luta por sua libertação. Um educador humanista, revolucionário, não há de esperar esta possibilidade. Sua ação, identificando-se, desde logo, com a dos educandos, deve orientar-se no sentido da humanização de ambos. Do pensar autêntico e não no sentido da doação, da entrega do saber. Sua ação deve estar infundida da presença nos homens. Crença no seu poder criador (FREIRE, 1987, p. 35).
\end{abstract}

Pelo exposto, a arte deve despertar nos alunos uma consciência que os estimule, sob uma perspectiva multicultural, a pensar como as diferenças fazem dos humanos ainda mais humanos. Além disso, ela tem o papel de sensibilizar, tornando a abordagem didática mais próxima e ligada aos sentimentos dos alunos. A proposta de se trabalhar a literatura como fonte de humanização convoca práticas de trabalho condizentes com a abordagem dialógica, no ato de criar condições para que os diversos sujeitos sociais desconfiem das abordagens realizadas no ensino tradicional, e se posicionem firmemente diante dos acontecimentos que os circundam.

\title{
CONSIDERAÇÕES FINAIS
}

Estudos crítico-sociológicos, com base não apenas nos estudos russos (BAKHTIN, 2006 [1979]; VOLÓCHINOV, 2017 [1929]), mas também em produções brasileiras direcionadas à 
literatura, como os de Candido (1972; 1985), vêm contribuindo significativamente para os estudos contemporâneos de linguagem, na medida em que impulsionam pesquisadores a examinarem cientificamente seus objetos de estudo.

Através do movimento teórico-analítico empreendido nesse trabalho, foi possível investigar a incidência do aspecto humanizador da literatura em obras, averiguando-se não apenas conteúdo, narrativa, autor e personagens, mas sobretudo suas condições históricas de produção, assim como a importância desses aspectos para compreensão de obras literárias e seus reflexos a partir de um corpo social.

Sob a égide do pensamento de Candido e alguns de seus interlocutores, esperamos que este trabalho possa contribuir para a promulgação de mais pesquisas no terreno da literatura, como um dispositivo de (des)continuidades teórico-metodológicas.

\section{REFERÊNCIAS}

BAKHTIN, Mikhail. O discurso em Dostoiévski. In: BAKHTIN, M. Problemas da poética de Dostoiévski. Rio de Janeiro: Forense, 2005 (1963).

BAKHTIN, Mikhail. O autor e a personagem. In: Estética da criação verbal. 6. ed. Tradução de Paulo Bezerra. São Paulo: Martins Fontes, 2006 [1979]). p. 6-20.

BAKHTIN, M. Estética da criação verbal. 6. ed. Tradução de Paulo Bezerra. São Paulo: Martins Fontes, 2006 [1979]).

BAKHTIN, M. Teoria do romance II: as formas do tempo e do cronotopo. Tradução, posfácio e notas de Paulo Bezerra. Organização da edição russa de Serguei Botcharov e Vadim Kójinov. São Paulo: Editora 34, 2018.

BARTHES, Roland. Aula: aula inaugural da cadeira de Semiologia Literária do colégio de França, pronunciado dia 7 de janeiro de 1978. 6. ed. São Paulo: Cultrix, 1992.

BLOOM, Harold. Como e por que ler. Tradução de Myriam Ávila, Eliana Lourenço de Lima Reis e Gláucia Renate Gonçalves. Rio de Janeiro: Objetiva, 2001.

BLOOM, Harold. O cânone ocidental. Tradução de Marcos Santarrita. São Paulo: Objetiva, 1995.

BOSI, Alfredo. Imagem, discurso. In: Discurso, V. 5, n. 5, p. 65-86. 1974.

BUORO, Anamelia Bueno. O olhar em construção: uma experiência de ensino e aprendizagem da arte na escola. $4^{\text {a }}$ edição. São Paulo: Cortez, 2000.

CANDIDO, Antonio. A literatura e a formação do homem. Ciência e cultura, v. 24, n. 9, p. 803-809, 1972. 
CANDIDO, Antonio. Literatura e sociedade: estudos de teoria e história literária. 7. ed. São Paulo: Nacional, 1985.

CANDIDO, Antonio. Formação da literatura brasileira. 5. ed. Belo Horizonte: Itatiaia, São Paulo: Edusp, 1975.

CANDIDO, Antonio. A literatura e a formação do homem. Remate de Males: Revista do Departamento de Teoria Literária, São Paulo, n. esp., p. 81-89, 1999.

CANDIDO, Antonio. O direito à literatura. In: Vários escritos. $4^{\mathrm{a}}$ ed. São Paulo/Rio de Janeiro: Duas Cidades/Ouro sobre azul, 2004. p. 169-191.

COMPAGNON, Antoine. Literatura para quê? Tradução de Laura Taddei Brandini. Belo Horizonte: Editora UFMG, 2009.

COSSON, Rildo. Letramento literário: teoria e prática. São Paulo: Contexto, 2007.

FISCHER, Ernest. A necessidade da arte. 9. ed. Rio de Janeiro: Guanabara Koogan, 1987.

GUMBRECHT, Hans. U.; JOBIM, José. L. Formas da teoria: sentidos, conceitos, políticas e campos de força nos estudos literários. Rio de Janeiro: Caetés, 2002.

MAGNANI, Maria do Rosário Mortatti. Leitura, literatura e escola: sobre a formação do gosto. 2. ed. São Paulo: Martins Fontes. 2001.

MATHEUS, Simone Guimarães. Os menores na leitura e os pormenores na escrita de Antonio Candido. Scripta, v. 23, n. 49, p. 244-259, 2019.

MCKEE, David. Elmer, o elefante xadrez. Trad. Mônica Stahel. São Paulo: WMF Martins Fontes, 2009.

MELO, Weslei Chaleghi de; PIMENTEL, Renan Guilherme. Literatura e cultura de massa: Por que ler os clássicos?. ANAIS. V Jornada de Didática e IV Seminário de Pesquisa do CEMAD, Universidade Estadual de Londrina. Londrina, 2018.

MEDVIÉDEV, Pável Nikoláievitch. O Método Formal nos estudos literários: introdução a uma poética sociológica. Tradutoras: Sheila Camargo Grillo e Ekaterina Vólkova Américo $1^{\mathrm{a}}$ ed. São Paulo: Contexto, 2016.

MEIRELES, Cecília. Romanceiro da Inconfidência. $3^{a}$ edição. Rio de Janeiro: Nova Fronteira, 2005.

MELlO, Ana Maria Lisboa de (Org). Cecília Meireles e Murilo Mendes (1901-2001). Porto Alegre: Uniprom, 2002.

ROCHA, Janine Resende. Limites do senti do e o papel do leitor na contemporaneidade. UFMG, 2010. 
SANTANA, Wilder Kleber Fernandes de. A ciência das ideologias e a filosofia da linguagem: nas tessituras de Volóchinov e o círculo de Bakhtin. Revista Diálogos, v. 7, n. 3, p. 205-220, 2019.

SANTANA, Wilder Kleber Fernandes de; SILVEIRA, Éderson Luís. Pelas v(e)ias de Antônio Candido: a literatura como fenômeno humanizador e fonte de transformação social. Revista Jangada. V.1, n. 13, p. 74-85, 2019.

SCHEIDT, Déborah. A teoria de Antônio Candido e a formação da literatura australiana. Revista Jangada. V.1, n. 13, p. 5-21, 2019.

SCHILLER, Friedrich. Cartas sobre a educação estética da humanidade. Tradução Roberto Schwarz. São Paulo: E.P.U., 1991.

TODOROV, Tzvetan. A literatura em perigo. Tradução Caio Meira. 3. ed. Rio de Janeiro: DIFEL, 2010.

TWAIN, Mark. As aventuras de Huckleberry Finn. Tradução Monteiro Lobato. São Paulo: Companhia Editora Nacional, 2005.

VENÂNCIO, Ana. Literatura infantojuvenil e diversidade. 2009. 257 p. Dissertação (Mestrado em Educação) - Universidade Federal do Paraná, Curitiba, 2009.

VOLOCHÍNOV, V. N. (círculo de Bakhtin). Marxismo e filosofia da linguagem Problemas fundamentais do método sociológico na ciência da linguagem. Tradução de Sheila Grillo e Ekaterina Vólkova Américo - Ensaio introdutório de Sheila Grillo. $1^{a}$ ed. São Paulo: Editora 34, 2017 [1929]. 